\title{
GOING DIGITAL
}

Using digital technology to conduct Oxfam's Effectiveness Reviews

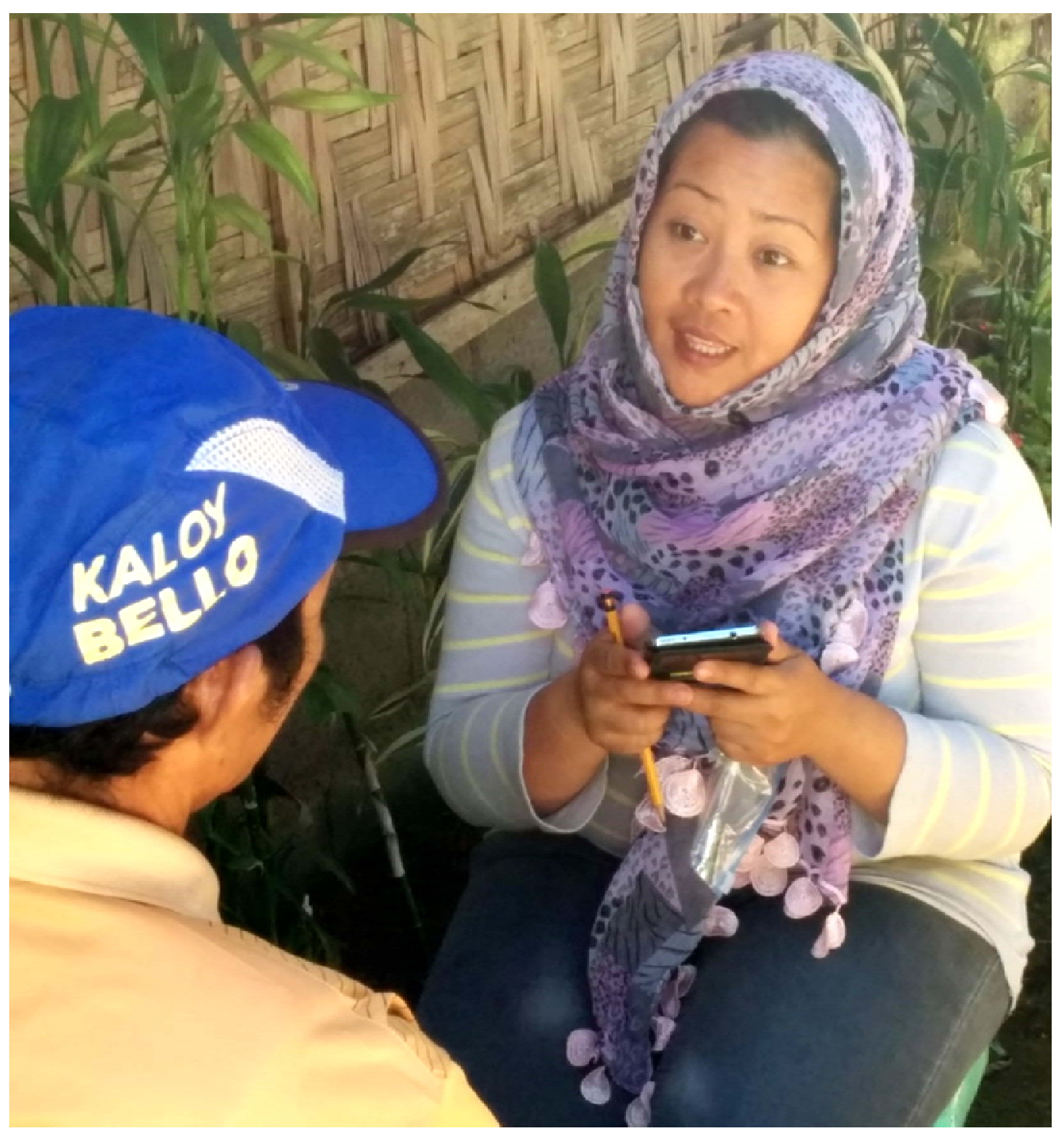

An enumerator in the Philippines carrying out an interview using a mobile phone. Photo by: Emily Tomkys/Oxfam

\section{Emilly Tomkys and Simone Lombardini}

\section{OXFAM GB}

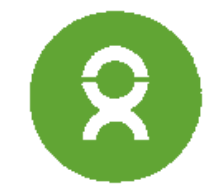




\section{CONTENTS}

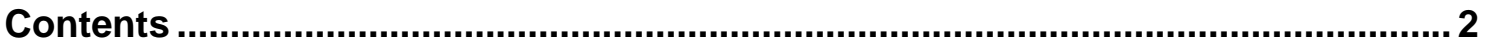

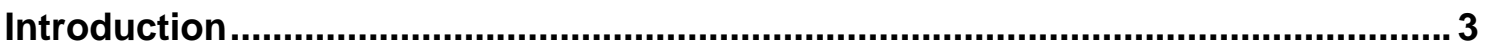

1. What is an Effectiveness Review? ................................................................... 4

2. Limitations of a paper-based data collection process ......................................... 5

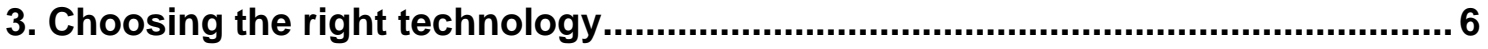

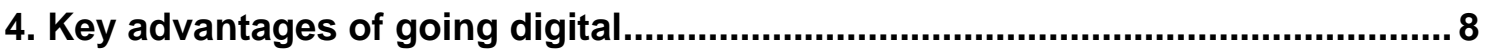

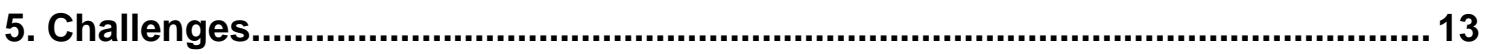

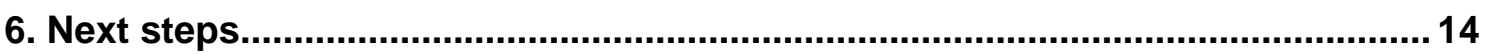

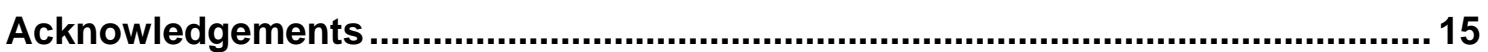




\section{INTRODUCTION}

Since 2011, Oxfam GB has been conducting rigorous impact evaluations to help understand and provide evidence of whether its work is resulting in positive change in the lives of the women and men with whom and for whom it works. Where previously Oxfam has relied on a paper-based survey data collection process, in 2015 it piloted digital surveying using Computer Assisted Personal Interview (CAPI). This involves training enumerators in the use of digital hand-held devices, such as tablets or smart phones, to record question responses while conducting interviews with the survey respondents. Oxfam has experience of using technology for data collection and its approach includes ensuring that ICT is considered as an enabler that adds value to the data-collection processes. A mobile methodology is being rolled out where Oxfam can be sure these are the appropriate tools for the context and its Responsible Data Policy can be adhered to. This paper reviews the use and value-add of digital surveys conducted for Effectiveness Reviews in the Philippines and in Thailand to highlight the benefits and challenges in comparison to the paper-based process traditionally used. 


\section{WHAT IS AN EFFECTIVENESS REVIEW?}

Oxfam GB's Effectiveness Reviews are rigorous impact evaluations conducted each year on a sample of randomly selected projects that have been implemented for at least two and a half years. The aim is to help understand and provide evidence of whether Oxfam's work is resulting in positive change in the lives of the women and men with whom and for whom Oxfam works. Large-scale development projects implemented at individual, household or community level are assessed through the use of ex post quasi-experimental impact evaluation techniques, which involve statistical analysis of information collected from both project participants and comparison households/individuals via household or individual surveys. For each evaluation conducted, there are on average 600 to 800 face-to-face one-hour interviews. During these interviews, trained enumerators administer a questionnaire designed to collect individual and household socio-economic characteristics relevant for the evaluation of the project under analysis.

Two projects from the Philippines and Thailand were randomly selected to be reviewed in the financial year 2014/15. The project in the Philippines, 'Scaling Up Sustainable Livelihoods in Mindanao' was supporting rural women and men in widening their livelihood options in order to achieve food security and sustainable income. Meanwhile the project in Thailand 'Development and Scaling Up of a Climate Change Community-Based Adaptation Model for Food Security in Thailand' aimed to increase the resilience and adaptation capacity of small-scale farmers to weather variability and climate change. Reports for both of these evaluations are currently being finalised and are likely to be published on the Policy and Practice website by late 2015. 


\section{LIMITATIONS OF A PAPER- BASED DATA COLLECTION PROCESS}

In order to collect household or individual surveys, the traditional approach to date has involved using questionnaires printed on paper and filled in manually by the enumerators during the interview. In the evening, the survey supervisors and coordinator check the quality and consistency of the responses reported in the questionnaires. Once all the interviews have been conducted and the fieldwork is concluded, data-entry clerks transcribe the information from the paper questionnaire into a digital format.

There are two main problems with the process as it stands:

1. The quality of the data - there are a number of opportunities for the introduction of errors during the data-collection and data-entry processes.

2. The time lag between data collection and when the data is ready for analysis -this can prevent or significantly delay feedback to communities.

Reducing the amount of errors is particularly important in the case of impact evaluations with a limited sample size. Research from Caeyers et al (2012) $)^{1}$ suggests that errors tend not to be randomly distributed across the sample, but are correlated with household characteristics, which can potentially introduce bias in the analysis if observations need to be dropped. For example, they found that household characteristics such as household size, female headed, and non-farm households are more likely to have non-consumption related estimates that could cause the observation to be dropped or the entry to require alteration at analysis stage.

Given the high probability of error during the data-entry process, this is normally conducted twice by two different data-entry clerks. Where there is a mismatch between the two entries, a third check is required. This process can take up to a month and costs roughly 10 per cent of the total budget for data collection. Given the timescales, it becomes challenging to analyse the data in time to offer feedback and verify findings with the communities that have been surveyed, this being an important accountability process for the communities involved in the study. 


\section{CHOOSING THE RIGHT TECHNOLOGY}

Using digital surveys using hand-held devices to record question responses is not new for Oxfam. A robust methodology implementing the use of digital tools for data collection has already been established based on earlier learning, particularly from its humanitarian work. In previous experiences, such as in a study conducted on displaced people by the typhoon Haiyan in the Philippines, the use of digital surveys for data-collection has demonstrated significant benefits in reducing time, as well as increasing Oxfam's accountability. However, the Effectiveness Reviews required a more advanced survey design and also the capability of the technology to work in multiple countries within a wide range of languages and contexts.

Choosing the right software was particularly important. Oxfam does not take a 'one fits all' approach to digital survey software. Projects and contexts have different requirements (e.g. connectivity needs, language compatibility, analytical requirements, etc.) and these are taken into consideration during the selection process. Many tools with varying mobile data collection functionality already exist, and it is important to find the most suitable software taking into account all the requirements as along with cost and ease of use.

For this specific pilot, the first requirement considered was flexibility with language. As the Effectiveness Reviews can take place in any of the 55 countries that Oxfam GB works in, the software needs to work flexibly in as many languages as possible, including the capability to use non-Latin characters. Secondly, because of the limited connectivity in some project areas, the tool needed to work entirely offline, from building the survey to having the data available for analysis. Thirdly, it was required that the tool have an advanced design functionality to accommodate the structure of long and complex survey questionnaires. Finally, as with every instance of data collection, the importance of data security was paramount. Using robust encryption procedures and hosting data in the EU were considered to be key requirements in the choice of the software. Based on these requirements, SurveyCTO was selected.

\section{Box 1: Oxfam's Effectiveness Review digital survey methodology}

The points below detail the top-level process of managing a digital Effectiveness Review for the year 2015/16:

\section{Step 1: Is using technology appropriate?}

In collaboration with teams on the ground, each Effectiveness Review undergoes an assessment that looks at the appropriateness of using technology within the context. Where mobile penetration and trust in technology is low, communities may feel uncomfortable being interviewed with a device they do not often see or do not necessarily understand. There could also be physical security concerns for enumerators carrying digital devices. These concerns are considered along with any logistical constraints, such as access to electricity and connectivity, which may require additional planning and resources.

\section{Step 2: Handset procurement}

Ideally, devices are already available in country due to other mobile data collection activities being regularly carried out there. However, when not available, procuring in country, where possible, is recommended to avoid custom issues, ensure that warranties are local and that the language is compatible. To ensure value for money, procurement should only take place where the use of the devices in country will go beyond the Effectiveness Review. 


\section{Step 3: Building the survey}

Surveys are built both in paper format and in Excel ready for upload into SurveyCTO. Having both digital and paper-based options means that enumerators can carry paper backups so that if anything happens to the device or the software, or if respondents would prefer to be interviewed using paper, this option is available for use immediately.

\section{Step 4: Handset set-up}

Devices are set up to maximise battery life and data security by changing the settings to dim brightness, placing phones on silent with no vibrate, deactivating LEDs, encrypting the device and password protecting it. The SurveyCTO app is installed as well as two free Android apps: Kids Place and a Mobile Device Management (MDM) app, such as Meraki, which allows the device owner to lock down the device and remotely track and wipe it if lost or stolen.

Handsets are branded and numbered with labels, and all details are added to a phone log for internal check-in/check-out purposes.

\section{Step 5: Training and guidelines}

Consultants and enumerators are trained in both the paper and digital processes, which means adding one extra day's training - usually increasing the duration of training from one day to two. Guidelines and troubleshooting tips for the software and digital device are also provided for reference.

\section{Step 6: Testing and piloting}

Testing the digital survey is paramount in ensuring that the automated logic, calculations, repeating sections, and branching are working as expected. Field tests are also required to pilot the questionnaire itself and to test the questions within a community.

\section{Step 7: Data collection and upload}

Once finalised, the survey is downloaded to each digital device. Ideally, enumerators will sign out the device each day and then sign it back in once the data collection is complete. This takes place with the device on flight mode to save battery life and it is the supervisors' responsibility to connect the devices and upload the data each evening while they are being charged. However, in cases such as the Philippines pilot, the sheer distance between locations means that devices may be signed out for the whole data-collection period and enumerators need to be trained in and responsible for uploading data as often as possible and also for charging their devices.

\section{Step 8: Downloading the data}

Once uploaded, data can be accessed and downloaded by the evaluation and research team regardless of their location. That means that while interviews are still being conducted, data uploaded on the server can be quality checked and enumerators can be guided if needed. Preliminary summary statistics can also be used to see early trends and to quickly feedback to communities. The data is then integrated into Stata, the statistical software package used for statistical and econometric analysis. 


\section{KEY ADVANTAGES OF GOING DIGITAL}

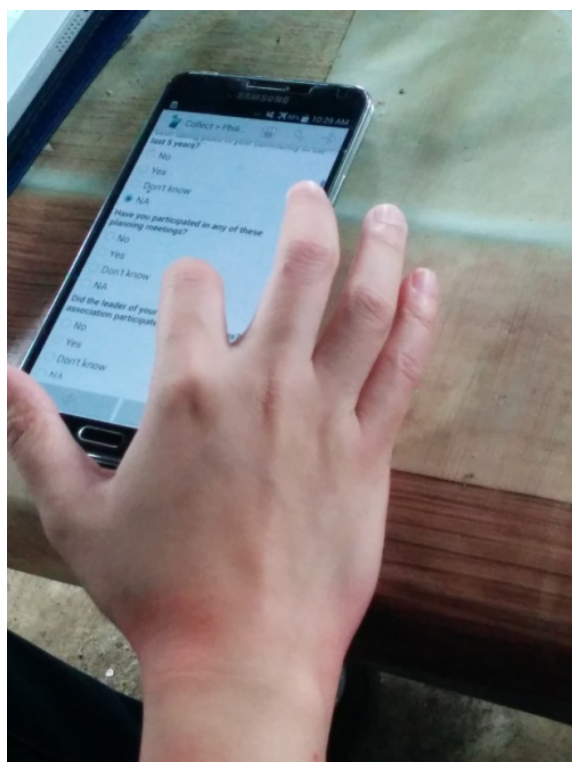

An enumerator in the Philippines conducting a mobile interview. Photo: Emily Tomkys/Oxfam
'Generally, the survey is good because of the device. It is easier and convenient to the user. No need to bring many forms. [It is] more efficient in doing things'

Jo and Elvy: Enumerators from fieldwork in the Philippines

During February and March 2015, Oxfam piloted the use of mobile devices for Effectiveness Reviews in the Philippines and Thailand. This section will describe the considerations used and the advantages found in using digital devices. These are summarised under five thematic areas: accuracy, timing, costs, accountability, and data security.

\section{TIMING}

Using digital devices has the potential to reduce the time it takes to complete the data-collection process. Firstly, introducing digital processes reduces the time required to conduct an interview. This can be seen in household surveys, which can be long and complicated, particularly in sections related to household/individual consumption. While with paper the enumerator has to learn when and how to skip questions that do not apply, the digital software assists the automation of the presentation of questions for the enumerator. Questionnaires can be programmed so that questions are presented interactively and questions that should not be asked are automatically skipped. Feedback from enumerators and respondents in both pilots was positive, with those surveyed in the Philippines stating that this 'is a fast survey in comparison to paper surveys', a positive response to the reduction in time.

Secondly, and possibly most importantly, using digital devices reduces the time required for Oxfam, partners and communities to obtain the data, due to the removal of the data-entry process. In the case of the Effectiveness Review process, converting data collected on paper into a digital file could take up to a month, but the use of digital devices allows access to the data almost instantly, as the supervisors or enumerators upload the data nightly.

Finally, using digital surveys also improves the quality of the data collected, which means that the time required for data cleaning is also reduced. Before being able to conduct statistical analysis, data need to be cleaned and variables properly labelled. Based on previous experience, this process can take several days. However when data are collected digitally, the 
structure and control imposed in the software means data are ready for variable construction in a significantly shorter length of time. This is because collecting data via digital surveys reduces the prevalence of outliers and automatically assigns a label to the variable based on the survey question.

However, despite an overall improvement in time taken to obtain an aggregated data set, it should be noted that preparing for a digital survey requires time to be allocated during earlier steps in the fieldwork process. For example, for SurveyCTO, building the survey in Excel takes time, especially for long and complicated questionnaires, as is the case in the Effectiveness Reviews. Similarly, additional time needs to be added to train the enumerators in conducting digital surveys. Enumerators should have the ability to complete the survey on paper as well as on a digital device, and paper backups should be carried at all times. This means that if there are technical faults, new security considerations in the project area or preferences expressed by communities not to use digital devices, paper copies are available so that the activities are not delayed.

Figure 1 illustrates the changes in the process when using digital technology rather than the traditional paper method.

Figure 1: Effectiveness Review process comparison

Digital survey

Questionnaire design
Coding digital questionnaire
Piloting and testing
Training (digital and paper)
Survey data collection
Comitor data quality

Data analysis
Paper version survey

Questionnaire design

Piloting

Training (paper)

Survey data collection

Data entry

Data analysis

\section{ACCURACY}

There are two main reasons why digital data allow more accurate measurements than data collected through the paper process. Firstly, the data-entry process is not needed, thereby removing several steps involving different people where errors can be introduced.

Secondly, depending on the tool selected, digital software can support the use of data-quality checks that improve the accuracy of data received. In addition to having constraints and skip logic, SurveyCTO allowed the introduction of automated checks across several questions, thereby reducing errors made at the point of entry by the enumerator. For example, calculation questions, such as the percentage of income from multiple sources adding up to $100 \%$, as shown in the picture below. 


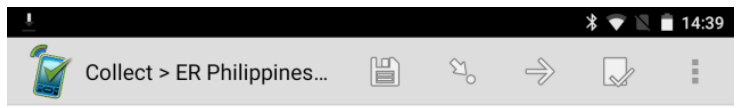

Your total household income does not equal $100 \%$ - PLEASE GO BACK AND CHANGE

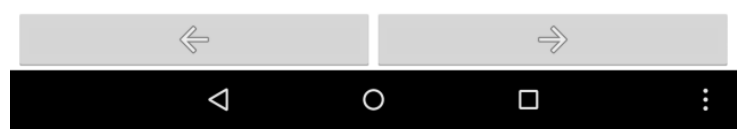

Screenshot from SurveyCTO Collect mobile app taken during the Philippines Effectiveness Review.

The technology also supports the remote monitoring of the data collected by each enumerator, raising flags if a particular enumerator is performing differently or collecting information that is significantly different from that of the rest of the team. Data-quality previously relied on the ability and diligence of the survey manager in checking all of the questionnaires and entries manually each evening. By automating much

'It is more efficient in doing things. Wrong entry can be corrected immediately due to the command 'Please go back and review the item"

Maria, one of our enumerators in the Philippines. of this process, survey managers, as well as key stakeholders, are able to monitor aggregated data, which automates much of a previously time-consuming process.

\section{ACCOUNTABILITY AND PARTICIPATION}

One key problem with data-collection processes based on paper questionnaires is the inability to analyse data quickly and the failure to provide prompt feedback to the communities interviewed. Using digital data-collection tools allows the researchers who set up the data collection process to access data instantly, generating preliminary summary statistics while data collection is still taking place in the field.

These preliminary statistics can be used for accountability and to feed back the results to those interviewed. Feedback has suggested that communities often feel that there is an abundance of data-collection taking place in their villages; however, they feel they have little information about the results and findings of these studies. ${ }^{2}$ Using digital surveys means that basic summary statistics and graphs can be generated and shared almost instantly while the data-collection team is still in the field. It should be noted that this process shouldn't in any way replace the need to share and circulate the results of the final evaluation to the communities.

The second advantage of processing data instantly is the possibility of exploring participatory methods. During the Effectiveness Review in Thailand, for example, the basic summary statistics generated were used as a basis for community meetings and focus groups, which were used to gather additional information and understanding of the project.

\section{DATA SECURITY}

Data security must be a priority for anyone collecting identifiable or personal information. Oxfam has been exploring how to be responsible with data and has recently produced a Responsible Data Policy. Paper surveys, in particular, can leave data very vulnerable as the process requires a number of steps where raw data is exposed. The information is physically stored on paper and so if the questionnaires are lost or stolen, either during the fieldwork or after it is concluded, it is relatively easy to access and interpret the information collected and transcribed. 
There are also more people involved in seeing the data: the enumerator, data-entry clerks, consultants and headquarters staff at a minimum.

With digital surveys, only the enumerators (at the point of data entry) and selected Oxfam staff with administrator rights are able to see all of the information. Others, such as the survey supervisors and survey coordinator, while monitoring the quality of the data, may see parts, but this can exclude anything deemed sensitive. As well as reducing the number of people seeing the data, the software used in this example allowed for a number of measures to be put in place to increase data protection. This included having servers hosted in the EU, using encryption during transmission as well as encrypting data of finalised questionnaires on the mobile device. Only those with the private decryption key could then download the survey data onto a computer.

In addition to the software used, encrypting the hardware device and installing it onto a Mobile Device Management (MDM) system safeguards the data so that Oxfam can remotely track and wipe the device in the event it is lost or stolen. GPS and photos were not captured during these pilots. To guarantee this, Oxfam installed a free application called Kids Place, which locks many of the features of the device out of use and only allows enumerators to access approved applications.

Informed consent and confidentiality agreements for data handlers remain in place regardless of whether the process is carried out in a digital or paper format. An additional paragraph is added to the informed consent for the digital survey explaining the use and effect of digital devices in data collection.

\section{COST}

The cost of digital surveys varies depending on the hardware and software used. The table below compares the cost of digital surveys with paper surveys under some relevant budget components. The estimates reported refer to the budget for data collection in Thailand in March 2015.

As shown in Table 1, the cost of the software is minimal compared with the typical cost of data entry. Thus, when excluding the cost of hardware procurement, savings of approximately $£ 1,300$ could potentially be made for a typical Effectiveness Review. With more and more country offices already having tablets and mobile devices that are regularly used to conduct data collections, it is likely that in many cases hardware will not need to be bought. Where hardware is not available, the money saved on data entry is unlikely to cover the full cost of procurement; it would depend on the local cost of devices and the number of devices required, as well as the sample size for the household survey. Therefore, buying devices for a one-off evaluation might not be justified in terms of value for money. However, country teams are increasingly using mobile devices, and so where there is interest and willingness to extend their use more widely to local data-collection exercises, the investment in deciding to 'go digital' may well be worth considering. The cost would vary by country, but if long-term use is planned for the devices, costs would be recouped through the savings made on data entry within a relatively short period of time. 
Table 1: Cost comparison

\begin{tabular}{|c|c|c|c|}
\hline & Paper & Mobile & $\begin{array}{l}\text { Cost } \\
\text { difference }\end{array}$ \\
\hline Software & $£ 0$ & $£ 162^{*}$ & $+£ 162$ \\
\hline Printing & $£ 200$ & $\begin{array}{l}£ 40 \text { ( } 20 \% \text { budgeted for } \\
\text { backup) }\end{array}$ & $-£ 160$ \\
\hline Data entry & $\begin{array}{l}£ 1,475 \text { (approx cost of } 4 \text { data entry } \\
\text { clerks \& } 1 \text { supervisor for } 15 \text { days) }\end{array}$ & $\begin{array}{l}£ 147 \text { (10\% budgeted for } \\
\text { backup) }\end{array}$ & - £1,328 \\
\hline $\begin{array}{l}\text { Total } \\
\text { (excluding } \\
\text { hardware) }\end{array}$ & $£ 1,675$ & $£ 349$ & $-£ 1,326$ \\
\hline Hardware & $£ 0$ & $\begin{array}{l}\text { Up to } £ 3,000 \text { (varies by } \\
\text { country but calculated based } \\
\text { on } £ 300 / \text { unit for } 10 \text { devices) }\end{array}$ & $+£ 3,000$ \\
\hline $\begin{array}{l}\text { Total } \\
\text { (including } \\
\text { hardware) }\end{array}$ & $£ 1,675$ & $£ 3,349$ & $+£ 1,674$ \\
\hline
\end{tabular}

*Software cost: additional savings will be made when more than one Effectiveness Review runs in the same month. 


\section{CHALLENGES}

A number of challenges could potentially prevent or disrupt the quality and feasibility of the data-collection process using mobile devices. As mentioned previously, not all of the survey data-collection exercises are necessarily suitable for digitisation. The type of data collected in an Effectiveness Reviews has been deemed conducive for mobile devices given that it involves quantitative household surveys. However, physical and digital security considerations need to be taken into account as well as the penetration of mobile phone usage within a community. Insecure contexts may not be suitable for using digital tools if carrying devices could put communities, enumerators, partners or Oxfam staff at risk. This factor means that not all future Effectiveness Reviews will be conducted using digital technology by default; rather each location will be assessed individually based on the project and context.

Even in an environment where technology is highly advanced and there is high penetration, conducting fieldwork using digital devices can face a number of practical challenges that should be taken into consideration when designing and implementing a data-collection exercise using mobile phones or tablets.

Firstly, the importance of building the survey correctly, and continuously testing before roll out, is extremely important. This is especially the case with long and complex surveys, as is invariably the case with questionnaires used for the Effectiveness Reviews, and using software where the build is based in Excel. Under tight time pressure, it is possible to incur coding errors that may affect the integrity of the data collected. The team of Oxfam Global Impact Evaluation Advisers have built base templates that will require minimal changes in order to mitigate this risk. It is advisable for multiple people to test the survey in order to explore all the possible variations and potential errors.

Secondly, there can be unexpected challenges that can impede digital surveys. During the survey in Mindanao in the Philippines, for example, 10 per cent of the data collection was carried out using paper because community leaders advised enumerators to avoid attracting attention due to rising tension and insecurities in the area.

Thirdly, weather conditions can also represent a challenge. The use of zip lock bags has helped enumerators contend with dust and rain, but in Thailand, the extreme climate made the devices so hot that they were uncomfortable to hold and enumerators had to put them on tables while inputting data.

Fourthly, there is often the challenge of dealing with varying levels of technological literacy. Despite the widespread accessibility of technology in many developing countries, enumerators might not always be familiar with mobile devices. This highlights the importance of training in helping them to gain confidence and develop their ability to navigate the devices. Oxfam provides guidelines and troubleshooting tips to aid the enumerators.

Finally, we have seen how using mobiles supports the sharing of preliminary summary statistics with the communities. However, it is particularly important to make sure that data is aggregated and presented in a manner where it is not possible to identify the individual respondents or put individuals or vulnerable groups at risk, for example by revealing private data. 


\section{NEXT STEPS}

This experience shows how ICT can add value and play a key role in Oxfam's programmes. Given the improvements gained in data security, accountability, accuracy, timing and even reducing costs where hardware is readily available, Oxfam's Impact Evaluation Advisers will be encouraging the rolling out of the use of digital surveys for the next round of Effectiveness Reviews wherever appropriate. Guidelines and standardised tools have been created for supporting this process.

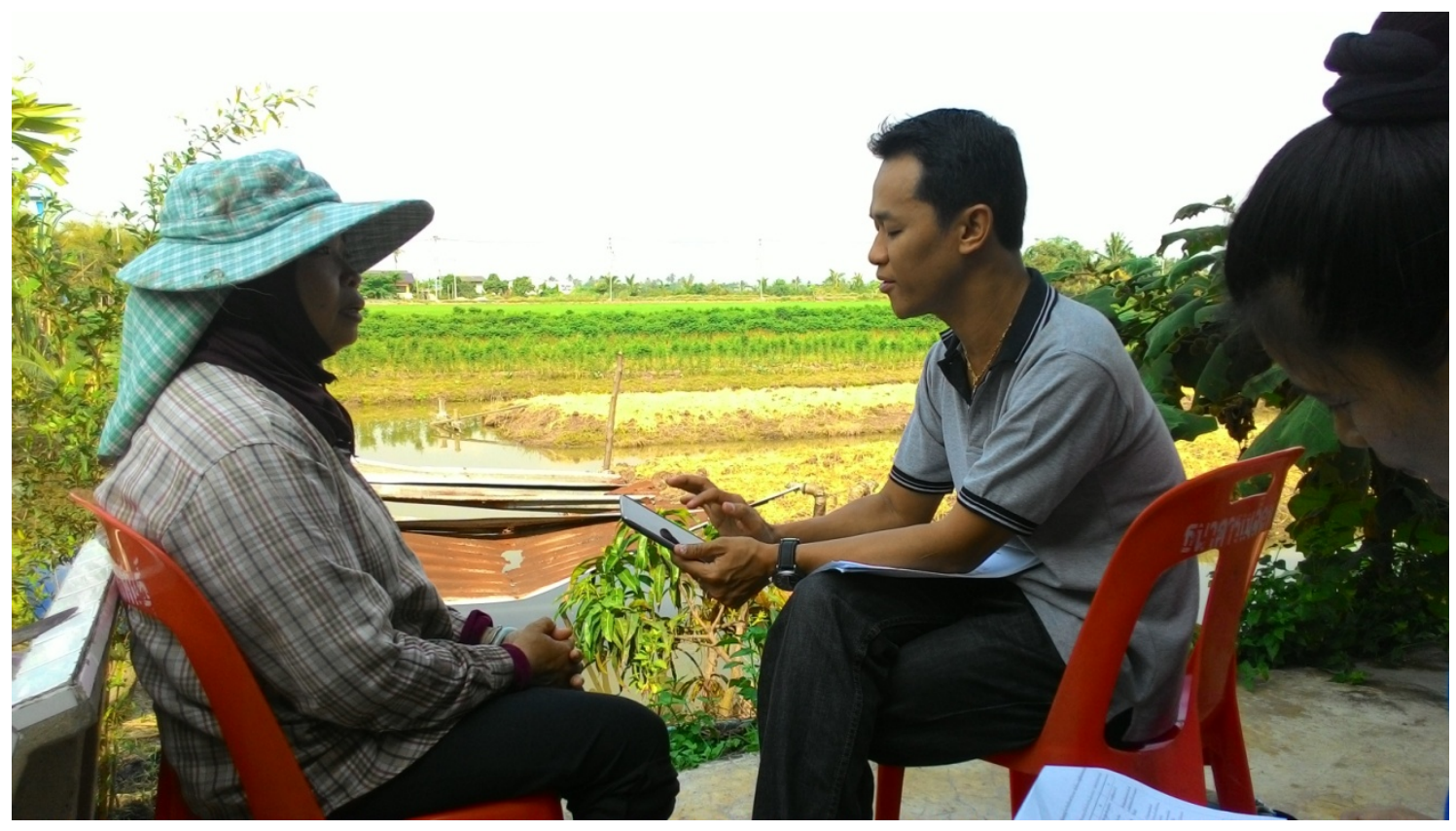

An enumerator in Thailand conducting a mobile survey interview. Photo: Rungthong Kramanon/Consultant 


\section{ACKNOWLEDGEMENTS}

We would like to thank Oxfam in the Philippines and Oxfam in Thailand for being so supportive during these two exercises. Particular thanks to Rodilyn A. Bolo, Dante Dalabajan and Irene De Leon from Oxfam in the Philippines, and Rizal Barandino, Edgar Catalan and Robert Raguro who managed the fieldwork in Davao, Philippines. Also particular thanks to Kasina Limsamarnphun and Nonthathorn Chaiphe from Oxfam in Thailand and Rungthong Kramanon who managed the fieldwork in Thailand. 
1 Caeyers Bet, Neil Chalmers, Joachim De Weerdt, (2013) Improving consumption measurement and other survey data through CAPI: Evidence from a randomized experiment, Journal of Development Economics, Volume 98, Issue 1, May 2012, Pages 19-33.

2 DFID (2015) Beneficiary Feedback in Evaluation. 

This case study was written by Emily Tomkys and Simone Lombardini. It is part of a series of papers and reports written to inform public debate on development and humanitarian policy issues.

This publication is copyright but the text may be used free of charge for the purposes of advocacy, campaigning, education, and research, provided that the source is acknowledged in full. The copyright holder requests that all such use be registered with them for impact assessment purposes. For copying in any other circumstances, or for re-use in other publications, or for translation or adaptation, permission must be secured and a fee may be charged. E-mail policyandpractice@oxfam.org.uk.

The information in this publication is correct at the time of going to press.

Published by Oxfam GB under ISBN 978-1-78077-952-2 in September 2015.

Oxfam GB, Oxfam House, John Smith Drive, Cowley, Oxford, OX4 2JY, UK.

\section{OXFAM}

Oxfam is an international confederation of 17 organisations networked together in more than 90 countries, as part of a global movement for change, to build a future free from the injustice of poverty:

Oxfam America (www.oxfamamerica.org)

Oxfam Australia (www.oxfam.org.au)

Oxfam-in-Belgium (www.oxfamsol.be)

Oxfam Canada (www.oxfam.ca)

Oxfam France (www.oxfamfrance.org)

Oxfam Germany (www.oxfam.de)

Oxfam GB (www.oxfam.org.uk)

Oxfam Hong Kong (www.oxfam.org.hk)

Oxfam India (www.oxfamindia.org)

Intermón Oxfam (Spain) (www.intermonoxfam.org)

Oxfam Ireland (www.oxfamireland.org)

Oxfam Italy (www.oxfamitalia.org)

Oxfam Japan (www.oxfam.jp)

Oxfam Mexico (www.oxfammexico.org)

Oxfam New Zealand (www.oxfam.org.nz)

Oxfam Novib (www.oxfamnovib.nl)

Oxfam Québec (www.oxfam.qc.ca)

Please write to any of the agencies for further information, or visit www.oxfam.org 